\title{
Outcomes after Multiligament Knee Injury Reconstruction using Novel Graft Constructs and Techniques
}

\author{
John Hee-Young Lee, $\mathrm{MD}^{1}$ James L. Cook, DVM, $\mathrm{PhD}^{1,2,3}$ Nichole Wilson, $\mathrm{RN}^{1,3}$ \\ Kylee Rucinski, MHA ${ }^{1,30}$ James P. Stannard, $\mathrm{MD}^{1,2,30}$
}

${ }^{1}$ Department of Orthopaedic Surgery, University of Missouri,

Address for correspondence James P. Stannard, MD, Department of Columbia, Missouri

2 Department of Orthopaedic Surgery, Thompson Laboratory for Orthopaedic Surgery, University of Missouri, Missouri Orthopaedic Regenerative Orthopaedics, University of Missouri, Columbia, Missouri Institute, 1100 Virginia Avenue, Columbia, MO 65212

${ }^{3}$ Department of Orthopaedic Surgery, Mizzou Biojoint Center, (e-mail: stannardj@health.missouri.edu).

University of Missouri, Columbia, Missouri

J Knee Surg 2022;35:502-510.

\begin{abstract}
Keywords

- multiligament knee injury

- multiligament reconstruction

- anterior cruciate ligament

- posterior cruciate ligament

- posterolateral corner

Clinical outcomes after reconstruction for multiligamentous knee injury (MLKI) can be consistently favorable. However, recent implants and technique advances may allow for improvement in outcomes. Our institution has developed novel graft constructs and techniques for reconstructions with preclinical data supporting clinical use. Our study purpose was to assess clinical outcomes after reconstruction for MKLI using our constructs and techniques. Overall success rate, failure/revision rates, return to work (RTW)/return to sports (RTS) rates, and complications were evaluated testing the hypothesis that novel methods would be associated with clinical benefits with respect to applications and outcomes compared with historical results. We reviewed a single-surgeon, longitudinal database of 42 patients who underwent multiligament reconstruction at our institution using these techniques for at least two-ligament injuries. Visual analogue scale (VAS) pain score and PROMIS (patient-reported outcomes measurement information system) were collected preoperatively and postoperatively at a minimum 1-year follow-up. Among these patients, 33 patients (mean age of 28.9 years, mean body mass index (BMI) of $33.2 \mathrm{~kg} / \mathrm{m}^{2}$, mean follow-up of 14.2 months) were included for outcomes analyses. With the definition of success as having a VAS score of less than or equal to 2 without revision/salvage surgery due to recurrent/residual instability or arthritis, overall success rate was $88 \%(29 / 33)$. The mean VAS scores improved from $5 \pm 2$ to $2 \pm 2$. The mean preoperative PROMIS mental health score was $36.2 \pm 7$, general health was $33.5 \pm 6$, pain was $62.7 \pm 8$, and physical function score was $29.4 \pm 3$. At the final follow-up, PROMIS MH was $50.2 \pm 10$, GH was $44.4 \pm 9$, pain was $54.3 \pm 9$, and PF was $42.6 \pm 8.4$. Return to work rate was $94 \%(31 / 33)$, and $52 \%(17 / 33)$ of patients were able to RTS at any level. Our results demonstrated excellent clinical outcomes associated with a primary success rate of $88 \%$ and RTW rate of $94 \%$. Intraoperative complications occurred in $9.5 \%$ of cases and revision and failure rates were $9 \%$ and $3 \%$, respectively. Our initial results suggest that multiligament reconstructions using novel graft constructs and techniques are safe and effective and can be considered an appropriate option for reconstruction of the full clinical spectrum of MLKIs.
\end{abstract}

received

July 6,2020

accepted

July 13,2020

published online

September 25, 2020 (c) 2020. Thieme. All rights reserved.

Thieme Medical Publishers, Inc.,

333 Seventh Avenue, 18th Floor,

New York, NY 10001, USA
DOI https://doi.org/

10.1055/s-0040-1716356. ISSN 1538-8506. 
Multiligamentous knee injury (MLKI) is relatively uncommon, but can cause significant functional impairment and devastating long-term sequelae, such as persistent pain and instability, inability to return to previous activities, decreased range of motion (ROM), and post-traumatic osteoarthritis (PTOA). ${ }^{1-3}$ Surgical treatment of MLKI has been reported to yield better functional outcomes in short- to medium-term follow-up in comparison with conservative treatment. Based on patient-reported outcomes in conjunction with assessments of knee stability and ROM, surgical reconstruction for MLKIs has been recommended over repair. ${ }^{4-8}$ However, failure rates after surgical reconstruction for MLKI remain as high as $40 \%$ and residual instability has been reported to be as high as $42 \%{ }^{9}$

When MLKI reconstruction is unsuccessful, patients experience pain, instability, dysfunction, and/or PTOA, which may result in need for revision surgery, need for salvage surgery (e.g., total knee arthroplasty [TKA], arthrodesis, amputation), or permanent disability. Poor outcomes after MLKI reconstruction have been reported to be associated with high-energy trauma, unaddressed ligament injuries at the time of index operation, high body mass index (BMI), concomitant cartilage injury, combined meniscal tears, bone tunnel widening, retained hardware, and mechanical axis malalignment. ${ }^{9-12}$ Revision reconstructions are challenging and associated with limited success. ${ }^{9}$ Failure requiring salvage surgery is also highly undesirable for patients. To minimize complications, revisions, and failures, MLKI graft constructs and surgical techniques should be designed to optimize graft strength, graft integration, knee stability, and functional graft healing to restore joint function and mitigate PTOA.

Recent advances in technology provide the potential to improve graft constructs and surgical techniques for MLKI reconstruction with respect to biologic and biomechanical parameters. These advances include all-soft-tissue grafts implanted into bone sockets using adjustable loop cortical suspensory fixation devices, use of quadriceps tendon as a source for autografts and allografts, and synthetic suture tape, or "internal brace," augmentation of grafts. ${ }^{13-23}$ Preclinical data indicate that together these advances can consistently result in immediate and maintained stability, fourzone graft-bone integration, and functional graft healing and remodeling. ${ }^{5,24-30}$ Importantly, these constructs and techniques allow for surgical reconstruction of all major ligaments in MLKIs while preserving bone stock and minimizing socket/tunnel-graft overlap and impingement. ${ }^{31-33}$

Based on preclinical evidence for safety and efficacy in conjunction with clinical evidence for successful singleligament reconstructions, the authors instituted a shift in practice to employ these novel graft constructs and techniques for reconstructions for MLKI and track outcomes in a prospective registry. As such, the purpose of the present study was to assess and report clinical outcomes for the initial cohort of consecutive multiligament reconstruction surgeries performed at the authors' institution using novel graft constructs and techniques. We hypothesized that the novel constructs and techniques would allow for surgical reconstruction of all major ligaments in MLKIs, minimizing socket/tunnel-graft overlap and impingement and yielding a high success rate based on postoperative pain, knee stability, and RTW in conjunction with low revision and failure rates.

\section{Methods}

With institutional review board approval and informed consent, patients enrolled in a prospective registry were identified for data analyses. Inclusion criteria were patients who sustained a MLKI, and subsequently underwent reconstruction performed by the senior author between November 2015 and November 2018 using the novel graft constructs and surgical techniques described ( - Table 1; -Fig. 1). Demographic characteristics including patient age, sex, BMI, injury patterns, and concomitant injuries were recorded. Operative data were also collected for analyses.

In an acute setting, once the patient has been stabilized, initial assessment starts with physical examination including soft tissue evaluation, focused neurology examination, and ankle-brachial index combined with serial vascular physical exams to rule out concomitant neurovascular injury. After reduction of the dislocated tibiofemoral joint, temporary stabilization is provided. Advanced imaging studies are obtained to delineate injured structures that are intra-articular and extra-articular. On the basis of physical examination and imaging studies, surgical planning is established. Examination under anesthesia (EUA) is emphasized in final decision-making for MLKI reconstruction.

After EUA, an arthroscopic intra-articular examination is performed to address concurrent meniscal and cartilage lesions. Arthroscopic drive-through signs in medial and lateral compartments supplement EUA findings. The debridement of remnant stumps of ruptured ligaments is performed. In the case of posterior medial corner (PMC) and posterior lateral corner (PLC) reconstructions, insertions of ligaments and isometric points on both the medial and lateral femoral condyles are identified and prepared in open fashion. Femoral and tibial sockets are created with graft-size-matched reamers. Grafts are passed. Initial docking and fixation into individual sockets are done using an adjustable length cortical suspensory fixation device. After graft conditioning with knee ROM, grafts are tightened through a sequential tightening of suspensory fixation devices in an order of posterior cruciate ligament (PCL), followed by the most unstable corner, and then the least unstable corner. Global stability is assessed. Selective re-tensioning of the grafts is done based on stability examination. Finally, stability is rechecked and confirmed. ${ }^{33}$

In all cases, injured ligaments were reconstructed. Allografts were used in all cases of PCL, PLC, and PMC reconstruction. For the anterior cruciate ligament (ACL), $24 \mathrm{ACL}$ reconstructions used quadriceps autograft, and 10 cases were reconstructed with quadriceps allograft on the basis of patient ages and activity levels. The Compass Knee Hinged External Fixator (Smith \& Nephew, Memphis, TN) was used in high-grade injury (total 12 patients, $28.5 \%$ ), six KDIII and six KDIV, to provide increased stability and protect reconstructed grafts during initial healing. ${ }^{34-36}$ 


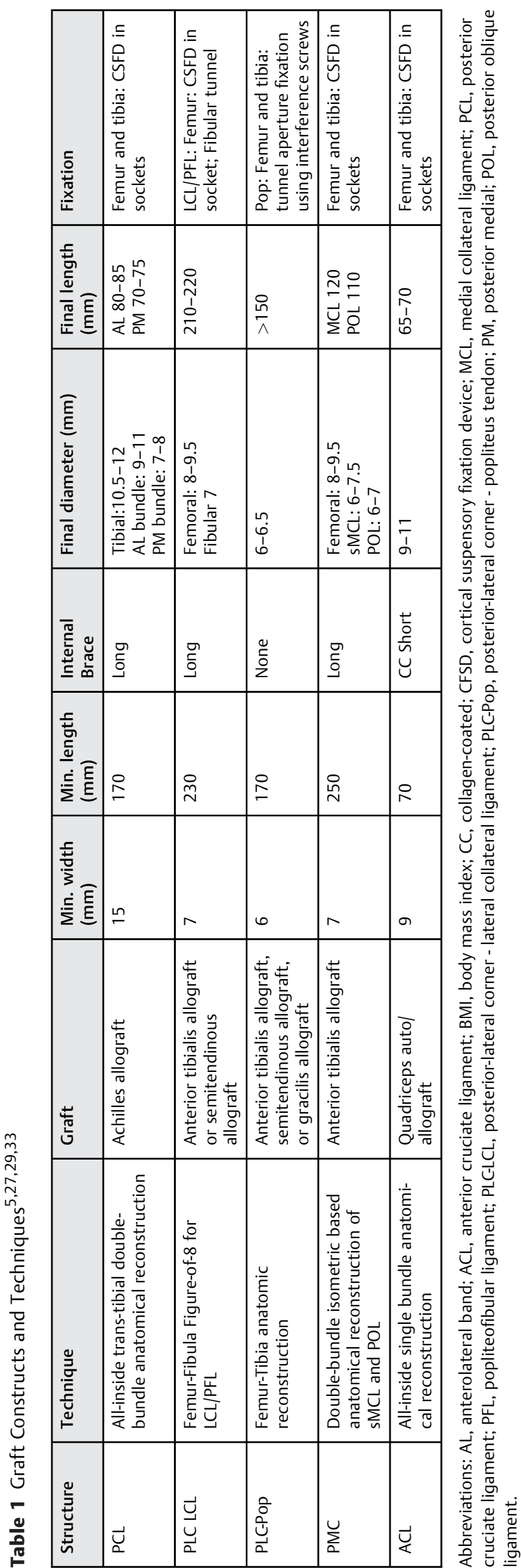

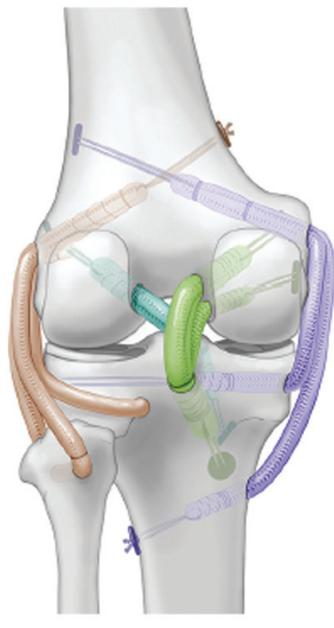
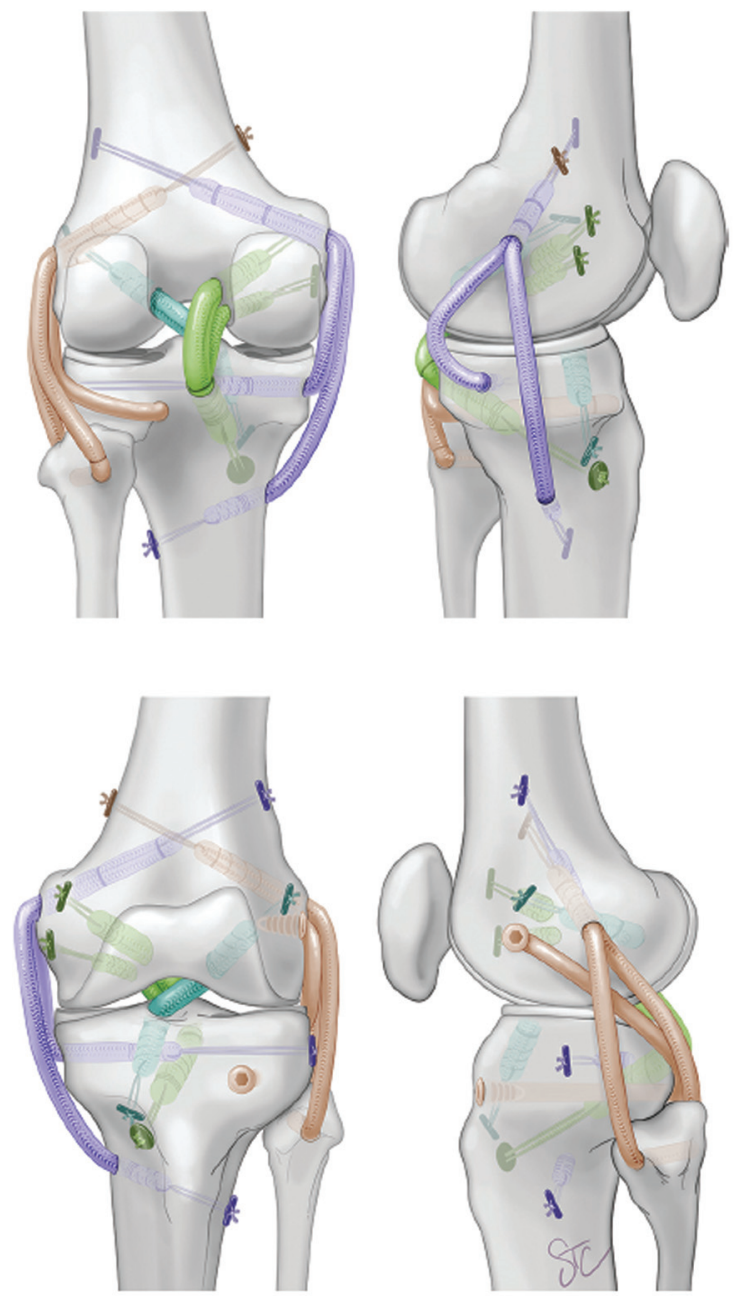

Fig. 1 Illustration depicting novel anterior cruciate ligament (ACL: turquoise), posterior cruciate ligament ( $P C L$ : green), posterior medial corner (PMC: purple), and posterior lateral corner (PLC: orange) graft constructs and techniques used for patients included in the present study. Top left $=$ posterior perspective; Top right $=$ medial perspective; Bottom left = anterior perspective; Bottom right = lateral perspective. Image Courtesy: Used with permission from The Curators of the University of Missouri.

A postoperative rehabilitation course was individualized for each patient on the basis of reconstructed structures, the patient's general condition, and desired activities. With novel reconstruction constructs and fixation techniques, we prefer an accelerated general protocol. In a setting of high-grade knee dislocation that requires more than three ligaments reconstructed; the compass hinged external fixators were used. ${ }^{36}$

The postoperative rehabilitation program is one of the important factors that affect the stability after MLKI reconstruction. The risks for arthrofibrosis and stiffness, and the risk for failure resulting from premature, aggressive rehabilitation, must be balanced. Following PCL and corner reconstructions, the patient starts weight-bearing as tolerated with crutches and the knee locked in full extension in a hinged knee brace on the first postoperative day. The need for and timing of staged ACL reconstruction also influences the postoperative course. 
Patients begin ROM at 0 to 30 degrees and progress as tolerated. A continuous passive motion machine can assist with this. Care should be taken not to progress the motion too quickly to allow early graft healing into the sockets. At 3 to 4 weeks, the hinged knee brace is unlocked during weightbearing activities. Physical therapy starts after the first 2 weeks. The main focus during the initial recovery period is to obtain and maintain motion.

By 6 weeks, the patient should be expected to have 0 to 90 degrees of active and passive knee motion, good patellar mobility, and normal gait without crutches. With all these goals achieved, patients can start the strengthening phase. The senior author continues knee bracing in MLKI patients full time for at least 3 months, and then continues it with any high stress activity for up to 18 months.

A custom-fit brace is recommended for therapy and athletic activities for the first 18 months following the reconstruction. Returning to heavy work and sports is gradually allowed during the period of 9 to 12 months post-surgery. The criteria for return to heavy work and sports vary depending on the activity level. Still, in general, patients return to strenuous activities when they have convincingly regained normal stability, motion, and strength of the knee. ${ }^{27}$

The primary outcome measure for analysis was success rate. Success was defined as the patients having a self-reported visual analogue scale (VAS) pain score $\leq 2$, documented knee ligament stability based on surgeon assessment, and RTW at any level with no need for revision at $\geq 1$ year after MLKI reconstruction. Knee stability in multiple planes was evaluated using a Lachman test, pivot shift test, posterior drawer test, dial test, and varus/valgus test at 0 and 30 degrees in comparison with the uninjured limb. Laxity was graded as negative,,+++ , or +++ , and soft or firm endpoint was recorded. All reported complications and reoperations were recorded. Revision was defined as a reoperation to address the primary MLKI reconstruction for any reason. Failure was defined as need for knee arthroplasty, arthrodesis, or amputation for any reason.

Secondary outcome measures include patient-reported outcomes measurement information system (PROMIS) scores and patient-reported VAS pain scores recorded preoperatively and at 3, 6, and 12 months and yearly after MLKI reconstruction. PROMIS is reported to correlate well with validated injury-specific outcome measures for MLKI as well as generalized measures such as Tegner and Lysholm. ${ }^{37}$ RTS was also determined at $\geq 1$ year postoperatively. When possible, anterior-posterior tibial translation relative to the femur was measured and recorded using the KT-2000 arthrometer. A side-to-side difference of $3 \mathrm{~mm}$ or more compared with the contralateral knee was defined as abnormal knee laxity.

\section{Statistical Analysis}

Descriptive statistics were calculated to report means, ranges, and percentages as appropriate. Fisher exact tests were used to assess for significant differences in proportions in success rates for variables of interest. Paired $t$-tests were used to assess for significant differences among preoperative and 1-year postoperative PROMIS and pain scores. Significance was set at $p<0.05$.
Table 2 Patient demographics

\begin{tabular}{|l|l|}
\hline Age & $28.9 \pm 10 \mathrm{y}$ \\
\hline Male & 32 \\
\hline Female & 10 \\
\hline BMI & $33.2 \pm 9.6 \mathrm{~kg} / \mathrm{m}^{2}$ \\
\hline High-energy injury mechanism & $25(59.5 \%)$ \\
\hline Low-energy injury mechanism & $17(40.5 \%)$ \\
\hline Acute reconstruction & $20(47.6 \%)$ \\
\hline Delayed reconstruction & $22(52.3 \%)$ \\
\hline
\end{tabular}

Abbreviation: BMI, body mass index.

Table 3 Knee dislocation injury classification

\begin{tabular}{|c|c|c|c|}
\hline Type & Injury & Number & Comments \\
\hline KD I & $\mathrm{ACL}$ or $\mathrm{PCL}$ & $16(38.0 \%)$ & \\
\hline KD II & $\mathrm{ACL}, \mathrm{PCL}$ & $1(2.4 \%)$ & \\
\hline KD III & $\begin{array}{l}\mathrm{ACL}, \mathrm{PCL} \text { and } \\
\text { Medial or } \\
\text { Lateral }\end{array}$ & $15(35.7 \%)$ & Medial 5, Lateral 10 \\
\hline KD V & $\begin{array}{l}\text { ACL, PCL, } \\
\text { PLC, PMC }\end{array}$ & 7 (16.7\%) & \\
\hline KD IV & $\begin{array}{l}\text { Associated } \\
\text { periarticular } \\
\text { fracture }\end{array}$ & $3(7.1 \%)$ & $\begin{array}{l}1 \text { medial tibial plateau } \\
\text { fracture } \\
1 \text { lateral tibial plateau } \\
\text { fracture } \\
1 \text { combined lateral } \\
\text { femoral condyle, lateral } \\
\text { tibial plateau, proximal } \\
\text { fibula fracture }\end{array}$ \\
\hline
\end{tabular}

Abbreviations: $\mathrm{ACL}$, anterior cruciate ligament; $\mathrm{KD}$, knee dislocation; $\mathrm{PCL}$, posterior cruciate ligament; PLC, posterior lateral corner; PMC, posterior medial corner.

\section{Results}

A total of 42 patients ( 32 males, 10 females) with average age of $28.9 \pm 10$ years and BMI of $33.2 \mathrm{~kg} / \mathrm{m}^{2}$ met inclusion criteria and had complete demographic and surgical data available for analyses (-Tables 2-4). With respect to mechanism of MLKI, 25 patients (59.5\%) sustained high-energy injuries, including motor vehicle accidents, and 17 patients (40.5\%) sustained low-energy sports-related injuries. Twenty cases (47.6\%) were reconstructed in the acute phase (within 4 weeks after initial injury) and 22 cases (52.3\%) were delayed for reconstruction (after 4 weeks post-injury). The mean time interval from the initial injury to index reconstruction surgery was 9.7 weeks when excluding two outlier revision cases. Thirty-three patients (79\%) with complete follow-up data (mean $=14.2$ months postop) were included for outcomes analyses.

The novel graft constructs and techniques were successfully implemented in all cases. Socket/tunnel-graft overlap and impingement requiring graft and/or fixation device repair and socket/tunnel revision occurred in four cases (9.5\%), including two femoral ACL-femoral PLC, one femoral PLC-femoral PMC, and one tibial ACL-tibial PMC POL. All four cases were successfully revised intraoperatively. 
Table 4 Concomitant injuries

\begin{tabular}{|c|c|c|}
\hline Injury & $\begin{array}{l}\text { Number of } \\
\text { cases }\end{array}$ & Comments \\
\hline $\begin{array}{l}\text { Peroneal } \\
\text { nerve } \\
\text { injury }\end{array}$ & $\begin{array}{l}7 \\
(16.6 \%)\end{array}$ & $\begin{array}{l}\text { All associated with posterior } \\
\text { lateral corner injury. } \\
\text { Two cases were combined with } \\
\text { popliteal artery injuries. } \\
\text { One case was also concurrent } \\
\text { with a proximal fibular fracture. }\end{array}$ \\
\hline $\begin{array}{l}\text { Popliteal } \\
\text { artery } \\
\text { injury }\end{array}$ & $\begin{array}{l}2 \\
(4.7 \%)\end{array}$ & $\begin{array}{l}\text { All required emergent vascular } \\
\text { consultation and all were for } \\
\text { KDIIIL MLKIs. }\end{array}$ \\
\hline $\begin{array}{l}\text { Meniscal } \\
\text { injury }\end{array}$ & $\begin{array}{l}18 \\
(42.6 \%)\end{array}$ & $\begin{array}{l}\text { Confirmed arthroscopically } \\
\text { and addressed accordingly with } \\
\text { meniscectomy or meniscus } \\
\text { repair (five isolated medial } \\
\text { menisci, three isolated lateral } \\
\text { menisci, ten combined medial } \\
\text { and lateral menisci). }\end{array}$ \\
\hline $\begin{array}{l}\text { Cartilage } \\
\text { injury }\end{array}$ & $\begin{array}{l}8 \\
(19 \%)\end{array}$ & $\begin{array}{l}\text { Confirmed arthroscopically } \\
\text { and treated with chondroplasty } \\
\text { (five medial femoral condyles, } \\
\text { two medial tibial plateaus, } \\
\text { and one lateral tibial plateau). }\end{array}$ \\
\hline
\end{tabular}

Primary success rate was $88 \%$ (29/33). When including three successful revisions of posterolateral corners, the overall success rate was $97 \%(32 / 33)$. RTW rate was $94 \%(31 / 33)$. RTS, for any level of sport, was 52\% (17/33) (-Table 5).

Twelve complications in 10 patients were reported (-Table 6). Three patients had arthrofibrosis and underwent manipulations under anesthesia and arthroscopic lysis of adhesions separately to the index reconstruction. Three patients had hardware irritation and underwent removal of cortical buttons; two of them were on the lateral tibia, and the other was on the medial tibia. Three patients experienced surgical site infection and were treated with debridement and local antibiotic-bead placement. Two of the three infection cases were in the patients who underwent PLC revisions.
Table 6 Complications

\begin{tabular}{|l|l|l|}
\hline & $\begin{array}{l}\text { Number of } \\
\text { cases }\end{array}$ & Comments \\
\hline Arthrofibrosis & $3(9.1 \%)$ & $\begin{array}{l}\text { MUA and arthroscopic lysis } \\
\text { at postoperative 3, 6, and 3 } \\
\text { and 11 months, } \\
\text { respectively. }\end{array}$ \\
\hline $\begin{array}{l}\text { Graft-implant } \\
\text { failure }\end{array}$ & $3(9.1 \%)$ & $\begin{array}{l}\text { PLC reconstruction failures } \\
\text { and subsequent revisions. }\end{array}$ \\
\hline $\begin{array}{l}\text { Hardware } \\
\text { irritation }\end{array}$ & $3(9.1 \%)$ & $\begin{array}{l}\text { Removal of cortical buttons } \\
\text { on two lateral tibias and } \\
\text { one medial tibia. }\end{array}$ \\
\hline Infection & $3(9.1 \%)$ & $\begin{array}{l}\text { Treated with multiple } \\
\text { debridements and } \\
\text { antibiotic beads. }\end{array}$ \\
\hline
\end{tabular}

Abbreviations: MUA, manipulation under anesthesia; PLC, posterior lateral corner.

One patient underwent TKA 17 months after surgical reconstruction of a KD V MLKI consisting of PCL tear, PMC tear, and ACL avulsion with comminuted medial tibial plateau fracture and complex lateral meniscus tear.

Three patients underwent PLC revision reconstruction. One case was associated with a comminuted proximal fibular fracture with the initial MLKI, which resulted in fibular nonunion and subsequent fibular tunnel failure. Two PLC revisions were associated with varus malalignment and underwent PLC revisions with simultaneous correctional osteotomies at 6 months and 8 months after primary MLKI reconstruction, respectively ( - Table 7 ).

Patient-reported outcomes based on PROMIS Global Health, Mental Health, Pain, Physical Function scores, and VAS Pain scores improved significantly $(p<0.05)$ at final follow-up (mean $=14.2$ months) with all PROMIS score means, except Physical Function, within the range for the normal healthy adult population, and a mean VAS pain score of 2 (-Fig. 2).

Table 5 Success, complication, return to work, and return to sport percentages

\begin{tabular}{|c|c|c|c|c|c|c|c|c|}
\hline Variables & Success rate & $p$-Value & Complication & $p$-Value & RTW & $p$-Value & RTS & $p$-Value \\
\hline $\begin{array}{l}\text { Female } \\
\text { Male }\end{array}$ & $\begin{array}{l}75 \% \\
92 \%\end{array}$ & 0.24 & $\begin{array}{l}50 \% \\
22 \%\end{array}$ & 0.17 & $\begin{array}{l}88 \% \\
96 \%\end{array}$ & 0.43 & $\begin{array}{l}63 \% \\
48 \%\end{array}$ & 0.69 \\
\hline $\begin{array}{l}\text { Age }<40 \\
\text { Age }>40\end{array}$ & $\begin{array}{l}89 \% \\
83 \%\end{array}$ & 1 & $\begin{array}{l}30 \% \\
17 \%\end{array}$ & 0.65 & $\begin{array}{l}96 \% \\
83 \%\end{array}$ & 0.33 & $\begin{array}{l}63 \% \\
50 \%\end{array}$ & 0.66 \\
\hline $\begin{array}{l}\mathrm{BMI}<35 \\
\mathrm{BMI}>35\end{array}$ & $\begin{array}{l}96 \% \\
70 \%\end{array}$ & 0.07 & $\begin{array}{l}13 \% \\
60 \%\end{array}$ & 0.01 & $\begin{array}{l}100 \% \\
80 \%\end{array}$ & 0.09 & $\begin{array}{l}57 \% \\
40 \%\end{array}$ & 0.46 \\
\hline $\begin{array}{l}\text { High energy } \\
\text { Low energy }\end{array}$ & $\begin{array}{l}94 \% \\
80 \%\end{array}$ & 0.31 & $\begin{array}{l}22 \% \\
40 \% \\
\end{array}$ & 0.45 & $\begin{array}{l}94 \% \\
93 \%\end{array}$ & 1 & $\begin{array}{l}56 \% \\
47 \%\end{array}$ & 0.73 \\
\hline $\begin{array}{l}\text { Lateral } \\
\text { Medial } \\
\text { Both }\end{array}$ & $\begin{array}{l}92 \% \\
90 \% \\
80 \%\end{array}$ & $>0.5$ & $\begin{array}{l}33 \% \\
30 \% \\
40 \%\end{array}$ & $>0.9$ & $\begin{array}{l}92 \% \\
100 \% \\
90 \%\end{array}$ & $>0.9$ & $\begin{array}{l}58 \% \\
60 \% \\
40 \%\end{array}$ & $>0.6$ \\
\hline $\begin{array}{l}\text { Bicruciate } \\
\text { not bicruciate }\end{array}$ & $\begin{array}{l}83 \% \\
93 \%\end{array}$ & 0.61 & $\begin{array}{l}33 \% \\
27 \%\end{array}$ & 0.72 & $\begin{array}{l}93 \% \\
94 \%\end{array}$ & 1 & $\begin{array}{l}39 \% \\
67 \%\end{array}$ & 0.17 \\
\hline $\begin{array}{l}\text { Acute surgery } \\
\text { Delayed surgery }\end{array}$ & $\begin{array}{l}80 \% \\
94 \%\end{array}$ & 0.31 & $\begin{array}{l}33 \% \\
27 \%\end{array}$ & 0.72 & $\begin{array}{l}93 \% \\
94 \%\end{array}$ & 1 & $\begin{array}{l}53 \% \\
50 \%\end{array}$ & 1 \\
\hline
\end{tabular}

Abbreviations: BMI, body mass index; RTS, return to sport; RTW, return to work. 
Table 7 Revisions and failures

\begin{tabular}{|l|l|l|l|l|}
\hline Procedures & Age/Sex/BMI & Type & Initial injury & Contributing factors \\
\hline TKA & $39 / \mathrm{M} / \mathrm{BMI} 34$ & KD V & $\begin{array}{l}\text { PCL, PMC, and ACL } \\
\text { avulsion with } \\
\text { comminuted MTP } \\
\text { fracture, LM tear }\end{array}$ & $\begin{array}{l}\text { Comminuted fracture-dislocation, } \\
\text { complex meniscal tear }\end{array}$ \\
\hline Revision PLC reconstruction & $38 / \mathrm{M} / \mathrm{BMI} 33$ & KD IV & $\begin{array}{l}\text { ACL, PCL, PMC, PLC } \\
\text { and comminuted } \\
\text { fibular head } \\
\text { fracture }\end{array}$ & Fibular tunnel failure \\
\hline $\begin{array}{l}\text { Revision PLC reconstruction } \\
\text { with simultaneous correctional } \\
\text { osteotomy }\end{array}$ & 24/M/BMI 40 & KD IV & ACL, PCL, PMC, PLC & Varus malalignment \\
\cline { 2 - 5 } & $37 / F / B M I ~ 45$ & KD IV & ACL, PCL, PMC, PLC & Varus malalignment \\
\hline
\end{tabular}

Abbreviations: ACL, anterior cruciate ligament; BMI, body mass index; KD, knee dislocation; PCL, posterior cruciate ligament; PMC, posterior medial corner; PLC, posterior lateral corner.

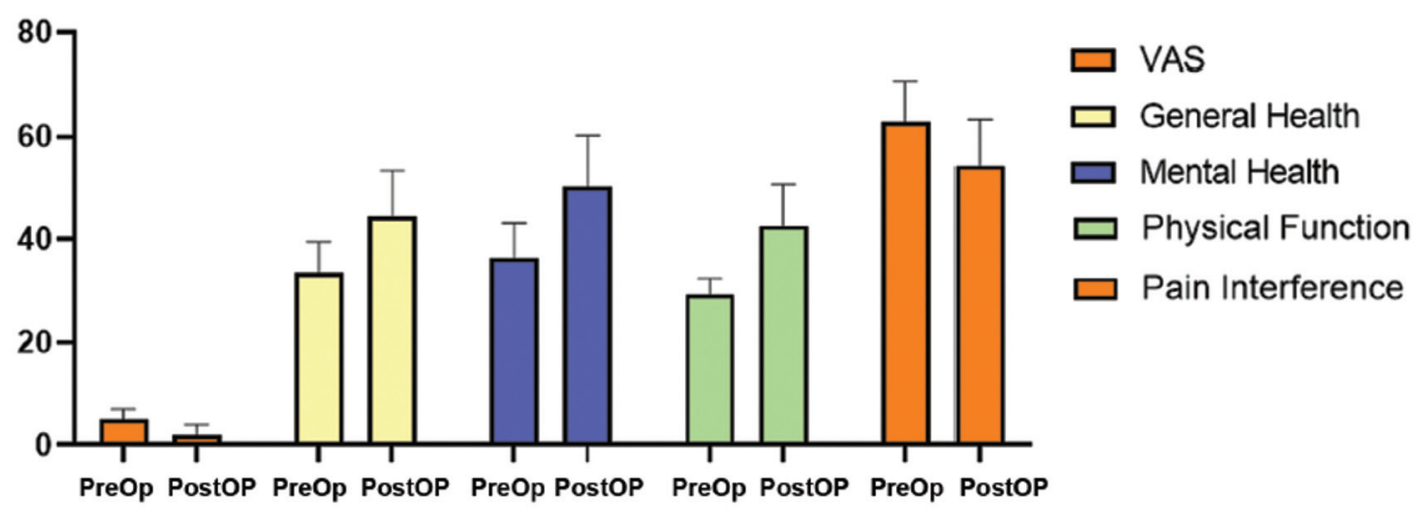

Fig. 2 Mean \pm SD patient-reported visual analogue scale (VAS) pain scores and patient-reported outcomes measurement information system (PROMIS) scores at preoperative and 1-year postoperative time points. SD, standard deviation.

Complete data for tibial translation measured using the KT-2000 arthrometer were obtained from 12 patients. The mean KT 2000 arthrometer side-to-side differences were $1.5 \pm 1 \mathrm{~mm}$ at the quadriceps neutral angle of 30 degrees and $1.5 \pm 1.3 \mathrm{~mm}$ at 70 degrees for these patients.

\section{Discussion}

The results of the present study allow for accepting the hypothesis in that novel graft constructs and surgical techniques allowed for surgical reconstruction of all major ligaments in MLKIs while minimizing socket/tunnel-graft overlap and impingement and yielding a high success rate based on postoperative pain, knee stability, and RTW in conjunction with low revision and failure rates. The primary success rate was $88 \%$ and overall success rate was $97 \%$ after three successful revisions. Patient-reported pain and function scores improved significantly at minimum 1-year follow-up and RTW rate was $94 \%$. Intraoperative complications related to the novel constructs and techniques occurred in 9.5\% of cases with all successfully revised at the time of index surgery. Revision and failure rates were low at $9 \%$ and $3 \%$, respectively. Taken together, these initial results compare very favorably to previous studies reporting outcomes after
MLKI such that these graft constructs and surgical techniques can be considered safe and effective for surgical reconstruction of a broad spectrum of MLKIs. As such, they have become the mainstay of MLKI treatment at our institution.

Data for the secondary outcomes analyzed in the present study also compare favorably to previous reports. While the incidence of persistent instability after MLKI reconstruction has been previously reported to range from 18 to $100 \%$ (mean $=42 \%)^{3,9}$ persistent instability was noted in only $12 \%$ of cases in the present study with at least 1 year of follow-up. Three of these (9.5\%) had varus and/or rotational instability and patients underwent successful revision of the PLC component of KD IV reconstructions, and two of these revisions included realignment tibial osteotomies. ${ }^{38,39}$ The other case of persistent instability was multidirectional in nature and occurred in a KD V knee with complete PCL and PMC disruptions, ACL avulsion, and a comminuted medial tibial plateau fracture with articular cartilage damage, and a lateral meniscal tear. Based on the instability and progression to PTOA, the patient opted for TKA at 17 months after the initial MLKI reconstruction. Interestingly, all of the persistent instability cases occurred in patients with high BMI (33-45), which was associated with a significantly higher complication rate and trended toward a significantly lower success 
rate in the present study. High BMI has been consistently reported as a risk factor for poor outcomes after MLKI. ${ }^{40-42}$

Restoration of function to allow for RTW or RTS is a key goal for MLKI surgery. In a recent systematic review, the rate for return to any level of work was reported at $88 \%$, and RTW with little or no modifications to preinjury level was $62 \%{ }^{43}$ Return to any level of sport after MLKI reconstruction has been reported to be approximately $60 \%$ with return to highlevel sport as low as 22 to $33 \% .{ }^{44}$ In another study, only $39 \%$ of patients were reported to be able to return to preinjury level of activity and $31 \%$ of patients returned to less physically demanding duty. ${ }^{27}$ Return to activity after MLKI reconstruction is influenced by multiple factors such as patient demographics, injury mechanism, concomitant injuries, surgical timing, and surgical techniques. ${ }^{9}$ High BMI, nonoperative treatment, high-energy mechanism of injury, neurovascular injury, compartment syndrome, traumatic knee arthrotomy, and intra-articular fracture were reported to be more prevalent in patients who were unable to RTW. ${ }^{44,45}$ For patients in the present study with at least 1 year of follow-up, 94\% returned to work and 52\% returned to sport. Only high BMI trended toward being a significant risk factor for inability to return to work in the present study.

Association of MLKI with PTOA has been well documented. After MLKI reconstruction, patients are reported to undergo TKA at an earlier mean age of 50 years compared with patients with a history of other knee surgery (mean age of 60$).{ }^{46}$ Similarly, patients had radiographic knee OA in $87 \%$ of injured knees at just 2 years after MLKI compared with 35\% of uninjured knees. ${ }^{10}$ In another study, 23\% of MLKI patients developed radiographic evidence of degenerative changes at a mean of 10 years after injury with $7 \%$ of patients undergoing TKA. ${ }^{47,48}$ Concurrent meniscus, articular cartilage, and subchondral bone injuries at the time of MLKI, nonsurgical treatment, chronic knee laxity, and age older than 30 years are risk factors for PTOA after MLKI. ${ }^{48-50}$ While the relatively short follow-up duration for the present study does not allow for conclusions to be made regarding development of PTOA after MLKI, the substantially lower initial revision and failure rates noted for patients in the present study suggest that the novel grafts and techniques have the potential to mitigate early-onset PTOA as well.

Based on the positive results noted for primary and secondary outcomes measures in conjunction with the patient population matching those in previous MLKI studies, the data from the present study suggest that the novel graft constructs and surgical techniques used have advantages for MLKI reconstruction. Taken together, it is likely that these potential advantages are related to robust graft constructs including synthetic internal brace augmentation for favorable immediate and sustained biomechanical function; all-soft-tissue grafts implanted into bone sockets using adjustable loop cortical suspensory fixation devices allowing for four-zone graft-bone integration and functional graft healing and remodeling, as well as repeated graft tensioning to diminish construct creep and achieve desired knee stability, and surgical reconstruction of all major ligaments in MLKIs while preserving bone stock and minimizing socket/tunnel-graft overlap and impingement. ${ }^{33}$ These components appear to be able to optimize graft strength, graft integration, knee stability, and functional graft healing to restore joint function and mitigate common complications and failures as realized in the present study.

We do recognize limitations for the present study. The patient population studied was heterogeneous with respect to patient demographics, comorbidities, concomitant injuries, and MLKI mechanism of injury and severity. While this heterogeneity represents the typical "real life" clinical scenario for MLKIs, it is associated with numerous potentially confounding variables that may affect broad application of the data. Similarly, because facets of the graft constructs and surgical techniques were designed and implemented concurrently as a shift in practice, it is not possible to delineate individual contributions of each to complications, success, or failure. In addition, PTOA was not assessed in this study based on the duration of follow-up data that was available for this trauma patient population.

\section{Conclusion}

MLKI reconstruction using novel graft constructs and surgical techniques was associated with a primary success rate of $88 \%$ and RTW rate of $94 \%$. Intraoperative complications occurred in $9.5 \%$ of cases and revision and failure rates were $9 \%$ and $3 \%$, respectively. Taken together, these initial results suggest that these constructs and techniques are safe and effective and can be considered an appropriate option for surgical reconstruction of the full clinical spectrum of MLKIs.

\section{Authors' Contributions}

J.H.-Y.L., J.L.C., N.W., K.R., and J.P.S. provided substantial contributions to research design, acquisition, analysis, and interpretation of data. J.H.-Y.L., J.L.C., N.W., K.R., and J.P.S. supported in drafting the paper and revising it critically. All authors have read and approved the final submitted manuscript.

\section{Conflict of Interest}

J.P.S. reports grants and personal fees from Arthrex, Inc., grants from DePuy Synthes, other from Journal of Knee Surgery, grants from National Institutes of Health (NIAMS \& NICHD), personal fees and other from Thieme, grants from U.S. Department of Defense, other from AO Foundation, other from American Orthopaedic Association, other from AO North America, grants from Coulter Foundation, other from Mid-America Orthopaedic Association, personal fees from Orthopaedic Designs North America, personal fees from Smith \& Nephew, outside the submitted work. J.L.C. reports grants and personal fees from Arthrex, Inc., personal fees from AthleteIQ grants from ConforMIS, personal fees from CONMED Linvatec, grants from Coulter Foundation, grants from DePuy Synthes, grants and personal fees from Eli Lilly, other from Journal of Knee Surgery, grants from Merial, other from Midwest Transplant Network, grants, personal fees and other from Musculoskeletal Transplant Foundation, grants from 
National Institutes of Health (NIAMS \& NICHD), grants from Purina, grants from Sites Medical, personal fees and other from Thieme, grants from TissueGen Inc, personal fees from Trupanion, grants from U.S. Department of Defense, grants from Zimmer-Biomet, outside the submitted work. Rest authors report no conflict of interest.

\section{Acknowledgment}

The authors wish to thank Stacy Cheavens, MS, CMI, for the figure illustrations featured in this article.

\section{References}

1 Sillanpää PJ, Kannus P, Niemi ST, Rolf C, Felländer-Tsai L, Mattila VM. Incidence of knee dislocation and concomitant vascular injury requiring surgery: a nationwide study. J Trauma Acute Care Surg 2014;76(03):715-719

2 Levy BA, Marx RG. Outcome after knee dislocation. Knee Surg Sports Traumatol Arthrosc 2009;17(09):1011-1012

3 Fanelli GC, Stannard JP, Stuart MJ, et al. Management of complex knee ligament injuries. J Bone Joint Surg Am 2010;92(12):2235-2246

4 Stannard JP, Brown SL, Farris RC, McGwin G Jr, Volgas DA. The posterolateral corner of the knee: repair versus reconstruction. Am J Sports Med 2005;33(06):881-888

5 Stannard JP, Stannard JT, Cook JL. Repair or reconstruction in acute posterolateral instability of the knee: decision making and surgical technique introduction. J Knee Surg 2015;28(06): 450-454

6 Levy BA, Fanelli GC, Whelan DB, et al. Knee Dislocation Study Group.. Controversies in the treatment of knee dislocations and multiligament reconstruction. J Am Acad Orthop Surg 2009;17 (04):197-206

7 Liow RY, McNicholas MJ, Keating JF, Nutton RW. Ligament repair and reconstruction in traumatic dislocation of the knee. J Bone Joint Surg Br 2003;85(06):845-851

8 Geeslin AG, Moulton SG, LaPrade RF. A systematic review of the outcomes of posterolateral corner knee injuries, part 1: surgical treatment of acute injuries. Am J Sports Med 2016;44(05): 1336-1342

9 Woodmass JM, O’Malley MP, Krych AJ, et al. Revision multiligament knee reconstruction: clinical outcomes and proposed treatment algorithm. Arthroscopy 2018;34(03):736-744.e3

10 Engebretsen L, Risberg MA, Robertson B, Ludvigsen TC, Johansen S. Outcome after knee dislocations: a 2-9 years follow-up of 85 consecutive patients. Knee Surg Sports Traumatol Arthrosc 2009; 17(09):1013-1026

11 Bratton AD, Harner CD, Miller TL. Revision surgery in the posterior cruciate ligament and multiple-ligament injured knee. In: Fanelli GC, ed. . The Multiple Ligament Injured Knee: A Practical Guide to Management. 3rd ed. New York, NY: Springer; 2019:317-332

12 King AH, Krych AJ, Prince MR, Sousa PL, Stuart MJ, Levy BA. Are meniscal tears and articular cartilage injury predictive of inferior patient outcome after surgical reconstruction for the dislocated knee? Knee Surg Sports Traumatol Arthrosc 2015;23(10):30083011

13 Aboalata M, Elazab A, Halawa A, Ahmed MS, Imhoff AB, Bassiouny $Y$. The crossing internal suture augmentation technique to protect the all-inside anterior cruciate ligament reconstruction graft. Arthrosc Tech 2017;6(06):e2235-e2240

14 Gilmer BB, Crall T, DeLong J, Kubo T, Mackay G, Jani SS. Biomechanical analysis of internal bracing for treatment of medial knee injuries. Orthopedics 2016;39(03):e532-e537

15 Trasolini NA, Lindsay A, Cooper J, George F. Internal bracing in multiple-ligament knee reconstruction. In: Fanelli GC, ed. The Multiple Ligament Injured Knee: A Practical Guide to Management. 3rd ed. New York, NY: Springer; 2019:475-488
16 Prince MR, Stuart MJ, King AH, Sousa PL, Levy BA. All-inside posterior cruciate ligament reconstruction: GraftLink technique. Arthrosc Tech 2015;4(05):e619-e624

17 Vertullo CJ, Piepenbrink M, Smith PA, Wilson AJ, Wijdicks CA. Biomechanical testing of three alternative quadrupled tendon graft constructs with adjustable loop suspensory fixation for anterior cruciate ligament reconstruction compared with fourstrand grafts fixed with screws and femoral fixed loop devices. Am J Sports Med 2019;47(04):828-836

18 Wood R, Robinson J, Getgood A. Anatomic posterolateral corner reconstruction using single graft plus adjustable-loop suspensory fixation device. Arthrosc Tech 2019;8(03):e301-e309

19 Lanzetti RM, Monaco E, De Carli A, et al. Can an adjustable-loop length suspensory fixation device reduce femoral tunnel enlargement in anterior cruciate ligament reconstruction? A prospective computer tomography study. Knee 2016;23(05):837-841

20 Colombet P, Graveleau N, Jambou S. Incorporation of hamstring grafts within the tibial tunnel after anterior cruciate ligament reconstruction: magnetic resonance imaging of suspensory fixation versus interference screws. Am J Sports Med 2016;44(11): 2838-2845

21 Smith PA, Piepenbrink M, Smith SK, Bachmaier S, Bedi A, Wijdicks CA. Adjustable-versus fixed-loop devices for femoral fixation in ACL reconstruction: an in vitro full-construct biomechanical study of surgical technique-based tibial fixation and graft preparation. Orthop J Sports Med 2018;6(04):2325967118768743

22 Freychet B, Desai VS, Sanders TL, et al. All-inside posterior cruciate ligament reconstruction: surgical technique and outcome. Clin Sports Med 2019;38(02):285-295

23 Kim SG, Kurosawa H, Sakuraba K, Ikeda H, Takazawa S, Takazawa Y. Development and application of an inside-to-out drill bit for anterior cruciate ligament reconstruction. Arthroscopy 2005;21 (08):1012

24 Cook JL, Smith P, Stannard JP, et al. A canine arthroscopic anterior cruciate ligament reconstruction model for study of synthetic augmentation of tendon allografts. J Knee Surg 2017;30(07): 704-711

25 Smith PA, Stannard JP, Pfeiffer FM, Kuroki K, Bozynski CC, Cook JL. Suspensory versus interference screw fixation for arthroscopic anterior cruciate ligament reconstruction in a translational largeanimal model. Arthroscopy 2016;32(06):1086-1097

26 Smith PA, Bley JA. Allograft anterior cruciate ligament reconstruction utilizing internal brace augmentation. Arthrosc Tech 2016;5 (05):e1143-e1147

27 Stannard JP, Deasis D. Surgical treatment of combined PCL medial and lateral side injuries: acute and chronic. In: Fanelli GC, ed. The Multiple Ligament Injured Knee: A Practical Guide to Management. 3rd ed. New York, NY: Springer; 2019:255-271

28 Nuelle CW, Milles JL, Pfeiffer FM, et al. Biomechanical comparison of five posterior cruciate ligament reconstruction techniques. J Knee Surg 2017;30(06):523-531

29 Stannard JP, Bauer KL. Current concepts in knee dislocations: PCL, ACL, and medial sided injuries. J Knee Surg 2012;25(04):287-294

30 Bauer KL, Stannard JP. Surgical approach to the posteromedial corner: indications, technique, outcomes. Curr Rev Musculoskelet Med 2013;6(02):124-131

31 Worley JR, Brimmo O, Nuelle CW, et al. Revision anterior cruciate ligament reconstruction after surgical management of multiligament knee injury. J Knee Surg 2020 (e-pub ahead of print). Doi: $10.1055 / \mathrm{s}-0040-1712969$

32 Worley JR, Brimmo O, Nuelle CW, Cook JL, Stannard JP. Incidence of concurrent peroneal nerve injury in multiligament knee injuries and outcomes after knee reconstruction. J Knee Surg 2019;32 (06):560-564

33 Cook JL, Cook CR, Bozynski CC, Bezold WA, Stannard JP. Development and assessment of novel multi-ligament knee injury reconstruction graft constructs and techniques. J Knee Surg 2022;35 (04):456-465 
34 Stannard JP, Schenck RC Jr, Fanelli GC. Knee Dislocations and Fracture-Dislocations. In: Bucholz RW, Heckmann JD, CourtBrown CM, Tornetta P III, eds. Rockwood and Green's Fractures in Adults. 7th ed. Philadelphia, PA: Lippincott Williams \& Wilkins; 2010:1861

35 Stannard JP, Brown SL, Robinson JT, McGwin G Jr, Volgas DA. Reconstruction of the posterolateral corner of the knee. Arthroscopy 2005;21(09):1051-1059

36 Stannard JP, Nuelle CW, McGwin G, Volgas DA. Hinged external fixation in the treatment of knee dislocations: a prospective randomized study. J Bone Joint Surg Am 2014;96(03):184-191

37 Stannard JP, Sheils TM, McGwin G, Volgas DA, Alonso JE. Use of a hinged external knee fixator after surgery for knee dislocation. Arthroscopy 2003;19(06):626-631

38 Trasolini NA, Korber S, Gipsman A, San AE, Weber AE, Hatch GFR III. Performance of PROMIS computer adaptive testing as compared with established instruments for multiple-ligament knee injuries. Orthop J Sports Med 2019;7(09):2325967119867419

39 Arthur A, LaPrade RF, Agel J. Proximal tibial opening wedge osteotomy as the initial treatment for chronic posterolateral corner deficiency in the varus knee: a prospective clinical study. Am J Sports Med 2007;35(11):1844-1850

40 Noyes FR, Barber-Westin SD, Albright JC. An analysis of the causes of failure in 57 consecutive posterolateral operative procedures. Am J Sports Med 2006;34(09):1419-1430

41 Werner BC, Gwathmey FW Jr, Higgins ST, Hart JM, Miller MD. Ultra-low velocity knee dislocations: patient characteristics, complications, and outcomes. Am J Sports Med 2014;42(02): 358-363
42 Ridley TJ, Cook S, Bollier M, et al. Effect of body mass index on patients with multiligamentous knee injuries. Arthroscopy 2014; 30(11):1447-1452

43 Dwyer T, Marx RG, Whelan D. Outcomes of treatment of multiple ligament knee injuries. J Knee Surg 2012;25(04):317-326

44 Everhart JS, Du A, Chalasani R, Kirven JC, Magnussen RA, Flanigan DC. Return to work or sport after multiligament knee injury: a systematic review of 21 studies and 524 patients. Arthroscopy 2018;34(05):1708-1716

45 Barrow AE, Sheean AJ, Burns TC. Return to duty following combatrelated multi-ligamentous knee injury. Injury 2017;48(04):861-865

46 Brophy RH, Gray BL, Nunley RM, Barrack RL, Clohisy JC. Total knee arthroplasty after previous knee surgery: expected interval and the effect on patient age. J Bone Joint Surg Am 2014;96(10): 801-805

47 Fanelli GC, Sousa PL, Edson CJ. Long-term follow up of surgically treated knee dislocations: stability restored, but arthritis is common. Clin Orthop Relat Res 2014;472(09):2712-2717

48 Moatshe G, Dornan GJ, Ludvigsen T, Løken S, LaPrade RF, Engebretsen L. High prevalence of knee osteoarthritis at a minimum 10-year follow-up after knee dislocation surgery. Knee Surg Sports Traumatol Arthrosc 2017;25(12):3914-3922

49 Pancio SI, Sousa PL, Krych AJ, et al. Increased risk of revision, reoperation, and implant constraint in TKA after multiligament knee surgery. Clin Orthop Relat Res 2017;475(06):1618-1626

50 Levy NM, Krych AJ, Hevesi M, et al. Does age predict outcome after multiligament knee reconstruction for the dislocated knee? 2- to 22-year follow-up. Knee Surg Sports Traumatol Arthrosc 2015;23 (10):3003-3007 